\title{
O JOGO DA TRADUÇÃO NOS LIMITES DO HAICAI
}

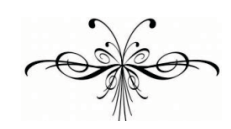

JOSÉ LIRA

\section{Resumo}

Este trabalho é um breve relato de algumas tentativas de tradução de haicais para outras línguas como uma espécie de jogo tradutório.

Palavras-chave: Tradução. Poesia. Haicai.

\section{Abstract}

This work is a brief account of some attempts on translating haiku into some different languages as a kind of translation game.

Keywords: Translation. Poetry. Haiku. 
$\mathrm{O}$ haicai é o tipo de poema de forma fixa mais difundido no mundo, tanto por meio de traduções de obras clássicas quanto pela produção de autores contemporâneos. Originário do Japão, o haicai - ou baiku, como é mais conhecido em outras línguas, - é, na verdade, um tipo de poema, não um poema como outro qualquer. Pelo menos para os seus teóricos e cultores mais tradicionalistas (entre os quais não me incluo, mas cujas ideias, de modo geral, acho válidas), haicai é haicai, não é poesia em sentido estrito. Quem faz haicais não é necessariamente poeta, e sim haicaísta.

Apesar de toda a recepção que teve e de toda a influência que supostamente exerceu na arte poética moderna, de inícios do século XX, quando passou a ser conhecido fora de sua terra natal, até os nossos dias - e apesar de toda a divulgação que hoje tem no abrangente universo da Internet, com milhares de portais, sítios, blogues e grupos dedicados exclusivamente ao seu estudo e difusão - o haicai é um gênero literário ainda mal compreendido e até desvirtuado entre nós. O haicai é, em síntese, o registro verbal, em linguagem simples e direta, de uma percepção sensorial momentânea baseada na observação da natureza, nela incluído o ser humano. Ou seja, não se vê como haicai um poema voltado para a exploração de efeitos rítmicos, estilísticos e prosódicos ou para os extravasamentos próprios da poesia lírica em geral.

O haicai que se faz hoje no mundo inteiro, apesar de preservar certos elementos da herança poética oriental, não é mais um poema japonês, assim como o soneto, para citar um só exemplo de poema de forma fixa muito cultivado na literatura ocidental, não é, apesar de suas origens, um poema italiano. Tanto um como outro são formas literárias adaptadas à cultura e às tradições de cada um dos países que os adotaram. O haicai brasileiro fala de nossa natureza e de nosso povo, e não é preciso aprender japonês nem ser adepto do zen-budismo para fazer bons haicais. No entanto, houve e ainda há equívocos por parte dos introdutores desse gênero textual entre nós e dos atuais poetas-baicaístas, que exprimem uma reflexão, uma fantasia, uma opinião, um gracejo ou um achado lírico-sentimental qualquer num poemeto de três linhas e o chamam de haicai, fiéis à falsa noção de que têm em mãos um poema minimalista de forma fechada $\mathrm{e}$ temática aberta. Mas o fato é que o haicai tem não apenas regras próprias, mas um jeito próprio de ser e de parecer haicai.

Os haicaístas porfiam pela exatidão do texto como representação inequívoca do real, coisa que os poetas não levam muito em conta. O poeta privilegia a Beleza. O haicaísta apega-se à Verdade. Um é subjetivo por inclinação, o outro é objetivo por princípio. Objetividade, aqui, não deve ser confundida com exatidão científica, pois é com nossa visão própria e inalienável que vemos e interpretamos o mundo. De fato, não há nada impessoal fora de nós e em nossa volta. Toda objetividade é subjetiva. Mas é a simples compreensão desse precário equilíbrio e o empenho em alterá-lo que faz do haicai um tipo de poesia diferente das outras.

Como parte da literatura universal atual, o haicai deve muito de sua identidade à tarefa do tradutor. O idioma japonês, dentro de suas limitações de espaço e de influência cultural, não teria tido força suficiente para viabilizar a sua 
disseminação pelo mundo. Foi por meio do inglês que o haicai conquistou, no século passado, os salões nobres da literatura ocidental (afora casos específicos como o nosso, em que a produção local foi, desde o início, para o bem ou para o mal, mais valorizada do que a tradução dos autores clássicos). Sem se prender à rigidez da métrica japonesa de 5-7-5 onji (sons), optando quase sempre pelo verso livre, o inglês presta-se bem à concisão do haicai. Hoje em dia é praxe, entre os haicaístas do mundo inteiro, divulgar os seus textos na Internet acompanhados da tradução para o inglês. Todos os concursos internacionais exigem a tradução inglesa ao lado do poema original. Há inclusive jornais japoneses que mantêm seções haicaísticas em inglês, injunção cultural às avessas que levou à presunção da existência de um tipo mal definido e mal explicado de world baiku.

Não há como negar que a língua inglesa é hoje um veículo de interação humana indispensável. Mas que não se fechem os olhos para a diversidade linguística desta nossa maravilhosa Babel. Por ser o haicai um poema tão curto, sem floreios e sem rima, na maioria das vezes é fácil achar boas soluções tradutórias. Mas em outras ocasiões é a sua concisão e o seu discurso próprio que dificultam uma tradução menos literal e ao mesmo tempo mais fiel.

Gosto de traduzir para o português, catados aqui e ali nas páginas virtuais, haicais feitos em línguas que sequer falo e mal conheço, apenas pelo prazer de captar (ou decifrar) algo de estranho e de sutil nessas vozes alheias. Gosto também de jogar com traduções de meus haicais para outras línguas que não o previsível inglês, como quem gosta de resolver quebra-cabeças para passar o tempo. É sobre esse jogo tradutório que fiz com alguns poucos textos de minha autoria que vou falar aqui. Vou também esboçar algumas noções básicas a respeito do haicai tradicional, isto é, do haicai como uma imitação (na acepção da imitatio medieval) do baiku original.

Começo com um haicai que tem por tema a Missa do Galo, culto restrito às pessoas de religião católica, até como forma de reiterar a universalidade do haicai, que não depende, como querem alguns, de atitudes práticas radicais nem de drásticas opções filosóficas ou religiosas. Não é preciso sequer uma febril inspiração poética nem, quiçá, uma refinada veia artística para fazer este tipo de poema:

Missa do Galo:

A velhinha a meu lado

Caiu no sono.

Que há de poético nessa ligeira e quase truncada exposição de uma cena tão simples? Muito pouco, dirão alguns, ou quase nada, muitos dirão, e é justamente aí que está a razão de ser do haicai, nessa fronteira entre poesia e prosa no qual ele se situa. Aqui começa a ficar clara a definição sugerida linhas atrás: o haicai é "o registro verbal, em linguagem simples e direta, de uma percepção sensorial momentânea baseada na observação da natureza, nela incluído o ser humano". Bem que não há definições absolutas, e essa mesma é incompleta, mas ela há de servir, neste trabalho, para situar o haicai em sua tradição e sua essência. 
Aceito para publicação na página Haicai Brasileiro do Jornal Nippo-Brasil, de São Paulo, é de supor que meu pequeno poema tem lá as suas qualidades (haicaísticas, como já se deduziu, e não poéticas). Esse jornal reúne quinzenalmente haicais submetidos por autores de todo o País, sempre com base em um tema obrigatório denominado kigo ou termo de estação.

O kigo é a palavra ou expressão que situa o haicai numa das quatro estações do ano. Considerado indispensável pela maioria dos haicaístas para a validação do poema como haicai e não como um texto poético qualquer, o kigo é um dos principais recursos objetivos de que se vale o haicaísta para exprimir a transitoriedade do universo e a mutabilidade dos seres e das coisas. Pode ser explícito, como sol de verão e noite de inverno, ou referir-se apenas contextualmente ao clima, à geografia, à fauna, à flora, a um fenômeno natural qualquer ou à própria natureza humana e suas manifestações (o haicai, é claro, também está presente na vida urbana moderna). Subentende-se, por exemplo, que é na primavera que certas árvores florescem e que no outono as folhas começam a cair, e convencionam-se correlações entre os fatos naturais e alguns estados de espírito como o frio e a melancolia, a alegria e o calor.

É certo que o kigo é um conceito estranho à poesia ocidental. Mas o haicai, já se sabe, é diferente, em muitos aspectos, de nossa poesia, e o kigo é um desses aspectos. Essa regra axial funciona às mil maravilhas no Japão e foi bem assimilada em outros países. No Brasil, ou pelo menos em algumas de nossas regiões, há certas variáveis difíceis de serem mensuradas, até porque não é tão clara, entre nós, a percepção da passagem das estações. Essa é, no entanto, uma questão que foge às limitações deste texto. Se um haicai é bem-sucedido ou não, isso não tem nada a ver com a falta de uso ou com o uso forçado do kigo. Depende muito mais de outros fatores, entre os quais, é claro, a capacidade de expressão do haicaísta.

A Missa do Galo, como tudo que se relaciona com as festas natalinas, faz parte de nosso repertório de termos de verão (pois é no verão que ocorrem) e é o que se convencionou chamar de kigo vivencial, não ligado diretamente à natureza, mas à atividade humana. Confesso que retratei nesse haicai da velhinha uma situação vivida quando, ainda criança, assistia a uma novena. Trata-se, portanto, de um haicai cuja produção foi guiada pela memória de um evento (e que além do mais foi adaptada ao tema exigido então pelo jornal), e não por uma experiência contextual. Por não levar em conta as objeções em relação a esse expediente antibaicaístico, paguei depois os meus pecados ao arriscar-me a traduzir o haicai para o italiano:

\section{Messa dell'Alba: \\ La vecchia accanto a me Addormentata.}

Foi frustrante para mim a constatação de que não poderia contornar uma perda inevitável na tradução, pois (por incrível que possa parecer) não existe em italiano uma esperada Messa del Gallo. Qualquer missa celebrada a qualquer hora do dia ou da noite na Itália, na época do Natal, é uma Messa di Natale. E Messa di 
Natale não sugere a imediata contextualização, tão almejada num haicai, de nossa Missa do Galo. Rezada à meia-noite, a Messa di Natale seria então uma Messa di Mezzanotte; e, um pouco mais tarde, de madrugada, uma Messa all'Alba ou Messa dell'Alba. Dei preferência a esta última locução por uma razão prática: era a única que manteria a métrica 5-7-5 do haicai italiano, correspondente, em nosso sistema de escansão, a um haicai curto de 4-6-4 sílabas, que é, por sinal (e por razões que não me cabe discutir aqui), o que tenho adotado em meus próprios haicais.

Essa inesperada complicação me levou a fazer uma tradução de minha própria tradução para avaliar o grau de (in)fidelidade tradutória desta última (os teóricos chamam esse recurso de retradução) e achei uma interessante equivalência para essa missa rezada antes do nascer do sol:

Missa das Almas:

Junto a mim uma velha

Adormecida.

Que é que resta do haicai original? Pouca coisa, talvez, levando-se em conta que o termo de estação não foi recuperado. Não há época própria no calendário anual para a celebração de uma Missa das Almas. Na primeira tradução, pelo menos, eu poderia alegar que alguns haicaístas italianos usam o que chamam de piccolo kigo (manhã, meio-dia, vento da tarde e noite de insônia, por exemplo), o qual - como também o faz Messa dell'Alba - já contextualizaria as noções fundamentais de transitoriedade e impermanência da natureza e das ações humanas, mesmo que limitadas ao espaço de um dia. Mas há tanta carga de simbolismo poético nesse último haicai, com a justaposição da Missa das Almas e da velha adormecida, que mais o considero uma partida ganha no final do jogo.

Qualquer ínfimo detalhe dispensável num haicai já é um defeito imperdoável. Haverá quem aponte três ou quatro defeitos neste outro haicai:

Três dias fora:

O gato na janela

Indiferente.

Em primeiro lugar, a ambiguidade: foi o autor ou foi o gato que passou três dias fora de casa? Creio que a maioria das pessoas sustentará sua própria versão sem sequer cogitar a existência de alternativa, mas essa possibilidade de opção está à mostra no texto, e não deveria estar, pois a clareza de linguagem é essencial num haicai - se bem que há quem veja nesse tipo de double entendre uma técnica normal e até recomendável. Alguns chegam a afirmar que se esforçam por incorporar a ambiguidade aos seus haicais. Mas a valorização da simplicidade e da diretidade linguística é consensual entre os haicaístas (pelo menos entre os que distinguem haicai de poesia lírica).

Embora as palavras ambiguidade e obscuridade sejam dadas como sinônimos nos dicionários, a verdade é que tudo que é obscuro é, de fato, ambíguo, mas nem tudo que é ambíguo é obscuro. Os adeptos da incorporação ao haicai das técnicas 
habituais da poética lírica confundem, em minha opinião, as noções de ambiguidade (própria da escrita) e múltipla interpretação (inerente à leitura). É certo que todo texto literário é suscetível de mais de uma interpretação ou explicação, por conta de convicções, imaginários, mundividências e outros aspectos subjetivos arraigados em cada um de nós. Cada um de nós pode apreender de modos diferentes um texto literário qualquer, mas isso não quer dizer necessariamente que ele é confuso ou equivocado. Ou seja, um bom haicai, feito em linguagem clara, concisa, objetiva, pode ter mais de uma leitura, e mesmo assim não ser ambíguo nem obscuro (à parte os casos de haicais humorísticos ou fesceninos, que se situam à margem da literatura haicaística tradicional).

Vem depois, nesse haicai, a antropomorfiz̧ação ou personificação: indiferença talvez não seja, a rigor, algo que possa ser atribuível aos animais. Embora usada uma vez ou outra até por Matsuo Bash $\square$ (1644-1694), o fundador do haicai, e Yosa Buson (1716-1783), que lhe seguiu os passos, e levada ao exagero pelo último dos grandes mestres clássicos japoneses, Kobayashi Issa (1763-1828), a personificação é combatida a ferro e fogo por zelosas legiões de haicaístas no mundo inteiro. Concordo que no haicai, como em tudo o mais, é sempre bom evitar as posições extremas. Haveria certo despropósito em dizer, por exemplo, que um gato está indignado, mas indiferente não me parece fora de lugar em relação à natureza felina do volver de olhos e lamber de patas (bem que todo gato é meio blasê).

Poderia haver outra restrição quanto à adequação ou não da palavra indiferente. A adjetivação, qualquer haicaísta sabe, deve ser evitada a todo custo. $\mathrm{O}$ haicai não qualifica nem define as coisas - apenas as situa no universo em que existem como coisas em si. O adjetivo só deve ser usado num haicai quando for imprescindível para compor a imagem, isto é, quando tiver um papel central e não apenas acessório no discurso. No caso desse haicai, creio que ele é aceitável. Já não seria adequado, por exemplo, nesse (e dificilmente noutro) contexto, ressaltar que o gato é ágil, belo ou gordo nem que a janela é, digamos, aconchegante.

Por último, esse é um muki haiku, ou seja, um haicai ao qual falta, para os mais exigentes, alguma coisa essencial. Como no caso da velha adormecida, podese dizer que esse é um haicai incompleto ou que não é um haicai, e sim um terceto à moda de haicai. Por quê? Porque o gato não é, por si só, um kigo e, como não há uma referência textual à passagem do tempo (nenhum dos versos remete a nenhuma das estações do ano), um poema desse tipo não seria aceito num concurso haicaístico tradicional ou nas páginas do Jornal Nippo-Brasil.

Esse é um dos haicais de minha autoria que resolvi traduzir para o francês. Captar em outra língua a objetividade e concisão do haicai é um bom jogo tradutório, e esse já me havia chamado a atenção, não por suas possíveis qualidades, mas por seus prováveis defeitos. Por sorte, a tradução dessa vez não me deu o mínimo trabalho. Qualquer aprendiz de idiomas teria feito algo assim:

Trois jours dehors.

Le chat à la fenêtre

Indifférent. 
Os haicaístas franceses apegam-se mais à explicitação do que à brevidade e diriam, no mínimo, que Le chat à la fenêtre / Est indifférent. De qualquer modo, a tradução literária tanto pode fazer um texto soar estranho em uma língua quanto, às vezes, revelar certos ínfimos detalhes que passam despercebidos em outra. Ao deixar de usar os dois-pontos no verso inicial, ficou-me a impressão de que não há mais ambiguidade: fui eu, sim, quem ficou fora de casa esses três dias.

Fiz até hoje poucos haicais sobre a aranha, essa pequena criatura que encanta e assusta ao mesmo tempo. Emily Dickinson diz que a aranha é "Filha enjeitada do Talento" (Neglected Son of Genius). Houve uma estranha coincidência na maneira como dois desses haicais foram feitos. Um deles me saiu em inglês, e o outro, em espanhol; só depois é que fiz a tradução para o português. Isso às vezes acontece quando estou absorto em algum trabalho ou numa leitura em outra língua (nada a ver com a surpreendente declaração de Jack Kerouac de que poderia fazer melhores haicais "considering the haiku situation in French first").

O primeiro, que compus há cerca de oito ou dez anos, foi um dever de casa. Eu participava na época de uma oficina e precisava compor, no prazo de três dias, um haicai usando a palavra chuva (rain). Não queria fazer um haicai fictício, ou seja, algo que não fosse fruto de minha própria experiência. O bom haicai é aquele que se faz porque se viu, ouviu, percebeu, captou, sentiu (ou até, em certos casos, lembrou) algo real, e tem o seu momento haicaístico próprio.

Por sorte, fazia dias que caía uma chuva fina e intermitente e vi numa bromélia, no terraço, uma pequenina aranha, cuja teia havia sido danificada pela água, atarefada em consertá-la (ou pelo menos assim me pareceu). E o haicai me saiu de imediato (reproduzo em seguida a tradução, neste e no próximo haicai):

Rainy weather-

The spider makes repairs

On his web.

Tempo chuvoso -

A aranha faz reparos

$\mathrm{Na}$ sua teia.

Em outra ocasião, ao sair de casa, depois de ter passado horas às voltas com alguns textos em espanhol, vi uma pobre aranha em situação bem pior:

Portón de bierro:

Una araña aplastada

En la bisagra.

Portão de ferro:

Uma aranha esmagada

$\mathrm{Na}$ dobradiça.

Não estou em condições de afirmar que esses dois flagrantes do real contêm o que os mestres chamariam de haimi ou sabor de haicai, algo muito difícil, 
se não quase impossível, de definir. Mas para mim eles são razoáveis. Apesar de sua dura e seca objetividade, contêm algo de poético e não deixam de sugerir, em nível interpretativo, um pouco mais do que dizem: no primeiro, a constatação de que mesmo os pequenos seres têm seus problemas domésticos e, no segundo, o contraste entre o pesado portão (que é uma espécie de teia de metal) e a frágil aranha. E a aranha, esta sim (não me perguntem por quê), é um kigo de verão.

Já quanto às traduções, é interessante notar que são exatamente ao pé da letra. Não me deram o menor trabalho quanto a qualquer aspecto formal ou funcional. Até parece que os haicais já foram concebidos geminados do jeito que aí estão. Seria bom se fosse sempre tão fácil assim fazer tradução poética. Até parece que nesses meus jogos tradutórios há muito mais ganhos do que perdas.

Mas vejamos por fim, ainda falando de aranhas, o caso deste haicai e de sua não tão fácil tradução:
A aranha chega -
Uma perna, mais outra,
E depois outra...

O haicai é um poema incompleto por natureza: é como a simples anotação ou o esboço apressado de um fato momentâneo vivenciado pelo haicaísta. Mas essa incompletude, como já foi dito, tem de ter uma contextualização adequada, e é muito vaga aqui a contextualização: não está dito aonde é que a aranha chega; não há uma definição quanto ao que ela está fazendo: ela apenas chega; o poema termina em aberto, deixando implícito que faltam aparecer aos olhos do haicaísta (e do leitor) mais outras pernas (pois todos sabem que a aranha tem oito pernas).

$\mathrm{Na}$ verdade, falta a esse haicai outra de suas exigências formais: a apresentação da imagem através de um quadro com cenário e ação. O haicai é, grosso modo, dividido em duas partes: um cenário, temporal ou local, em geral no primeiro ou no último verso, e a ação, que engloba o(s) seu(s) agente(s), nos outros dois. Nos outros haicais vistos aqui, o cenário está explícito ou é facilmente subentendido. Nesse, é necessário um esforço de imaginação muito maior por parte do leitor. Parece até, alguém diria, que se trata de uma tradução mal feita.

Venho tentando ultimamente, como uma variação de meus jogos de tradução haicaística, transpor para nossa língua alguns dos haicais dos mestres japoneses de que mais gosto. Depois de ter tentado traduzir um ou outro texto de Basho, Buson e Issa, posso assegurar, no entanto, que minha inaptidão e perplexidade em relação à sua língua são cada vez maiores. Que dizer então de tentar verter para o japonês um haicai escrito originalmente em português? Esse último haicai da aranha serviria?

Segue abaixo o resultado. Transcrevo apenas a transliteração romanizada da escrita ideográfica e silábica japonesa, dispensando, como é usual nesses casos, a linearização dos versos e o uso de maiúsculas:

kumo ga kite bikizuru ashi to ashi to ashi 
Numa tradução literal, teríamos (seria o caso de esclarecer, neste caso, que o japonês não possui artigos, vale-se de certas partículas não traduzíveis e omite algumas palavras funcionais indispensáveis em outras línguas):

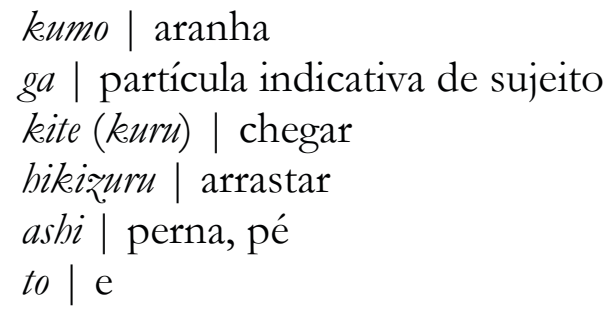

Não sei se consegui dar uma forma aceitável a esse texto. Trata-se, de qualquer modo, de uma tradução (melhor diria adaptação) provisória. Espero poder rever estas notas daqui a dez ou vinte anos, sabendo muito mais do que sei hoje, para, se for o caso, corrigir o que fiz como aprendiz dessa língua especial, que é o haiku, dentro da língua especial que é o japonês. Mas sinto que algo não está bem neste meu jogo, cujo teste de reversibilidade tradutória daria um pífio resultado:

Lá vem a aranha -

Arrasta as suas pernas

Perna após perna.

Ou, noutra tentativa menos convencional:

Chegou a aranha:

Vem arrastando a perna,

A perna, a perna...

Ou qualquer coisa nessa direção. E aqui já fica, e desta vez com mais força, a impressão de que nada resta do haicai anterior. A introdução, na versão em japonês, de um segundo verbo (bikizuru), inexistente (embora implícito) no original, deve ter sido a causa desse desastre. A tradução de meu haicai japonês para o português ficou prosaica e pesada demais. Empiorou o haicai original, que já não era lá essas coisas.

O haicai, já se viu, precisa de um toque de poesia para ser haicai. Mas num jogo tradutório nem sempre há solução para algo tão abstrato e imponderável.

Traduzir um poema, por menor que ele seja, é quase sempre uma questão de talvez sim e ainda não. Há frases poéticas em uma língua que, traduzidas, tornamse áridas e banais em outras. A poesia é, em princípio, intraduzível, não por usar palavras que extrapolam qualquer contexto real, mas pelo fato de que ela (a poesia) está impregnada do próprio signo e não se vale só de sua significação. Não está basicamente no que a palavra quer dizer, mas no que ela (a palavra) diz:

Mesmo assim se traduzem poemas e haicais todos os dias. Apesar de que são poucas as que transcendem pretensões meramente didáticas, uma boa 
tradução pode transmitir essa característica peculiar do haicai, o já citado haimi, e ainda ser valorizada como poesia. O mais difícil é captar na origem essa sóbria beleza (wabi) baseada na concentração, num poema tão curto, de exigências formais que só de longe tocamos aqui - mas baseada, sobretudo, num estado meditativo que nos induz a perceber algo sutil nas coisas mais simples, numa nostalgia existencial (sabi) centrada no aqui e agora que é a marca da evanescência com que os seres e as coisas se integram à natureza. Visto dessa forma, o haimi é uma epifania, uma revelação, e a tradução, pobre dela, nem sempre pode fugir da obrigação e da rotina.

Mas essa é só minha opinião atual. Posso pensar de outro modo amanhã. Nada é o que é: ainda ontem foi hoje. Uma das coisas que mais me atraem no haicai é justamente a sua inesgotável capacidade de me surpreender e me fazer mudar. E uma das coisas que me prendem a esse jogo de palavras da tradução é a possibilidade de fazer essas mudanças sem temer eventuais surpresas.

JoséLira

Tradutor

liraj@oi.com.br

NOTA: Agradeço a Araken Guedes Barbosa e Luiza Nana Yoshida pela leitura e correção deste texto. 